\title{
CHARACTERIZATION OF SISAL FIBERS BY INFRARED, UV-VIS DIFFUSE REFLECTANCE AND SCANNING ELECTRON MICROSCOPY
}

\author{
AMORIM, Laudenor ${ }^{1 *}$; DE MELO, Santino Loruan Silvestre ${ }^{2}$, DE PAIVA JÚNIOR, Sérgio Luís \\ Moura $^{3}$; DE DEUS, Enio Pontes ${ }^{4}$; \\ 1,2,3,4 Universidade Federal do Ceará, Campus do Pici, Departamento de Engenharia Metalúrgica e de Materiais, \\ Avenida Humberto Monte, S/N, CEP 60.440-554, Fortaleza - CE, Brasil \\ (Fone: +55 853366 9619; Fax: +55 853366 9070) \\ ${ }^{*}$ Autor correspondente \\ e-mail: quimicolaudenor@gmail.com
}

Received 10 May 2018; received in revised form 16 July 2018; accepted 25 July 2018

\section{RESUMO}

O desenvolvimento de materiais mais resistentes e baratos foram importantes para o surgimento de compósitos, materiais que são resultantes da mistura de dois ou mais componentes distintos, com propriedades melhoradas. $\mathrm{O}$ uso de fibras vegetais como carga de reforço em matrizes poliméricas diminui o custo e mantém a qualidade do produto. A boa resistência ao impacto e facilidade no cultivo do sisal foram de interesse para caracterização das fibras utilizando técnicas de infravermelho e UV-Vis por reflectância difusa, com o objetivo de adaptar a metodologia existente e aumentar a adesão fibra-matriz sem danificar as fibras. Para a caracterização morfológica, utilizou-se microscopia eletrônica de varredura. O mapeamento da composição química das fibras foi obtido com o auxílio da espectroscopia de raios $\mathrm{X}$ por dispersão de energia. Foram empregados tratamentos à base de $\mathrm{NaOH} 2 \%$ e acetilação com ácido acético e anidrido acético na proporção $(1: 1,5)$ e as principais mudanças observadas foram a remoção de impurezas e a menor quantidade de água absorvida na fibra acetilada, o que possibilita uma melhor adesão das fibras com o polímero. Busca-se empregar as fibras na produção de compósitos com polipropileno e polietileno e aplicá-los em peças automotivas como para-choques, tanques de combustível e revestimentos internos.

Palavras-chave: Compósitos; Fibras de sisal; Acetilação; Tratamento químico.

\section{ABSTRACT}

The development of more resistant and inexpensive materials were important for the emergence of composites, materials that are the result of the mixing of two or more distinct components with improved properties. Vegetable fibers reinforced polymer matrix composites help to reduce costs as well as to preserve product quality. Sisal fibers are important due to good impact resistance and availability. Thus, the characterization used infrared spectroscopy and UV-Vis diffuse reflectance. The main purpose was to adapt the methodology used, in order to improve fiber-matrix adhesion, but without risks of fiber defibrillation. Scanning electron microscopy was used to obtain the morphological characterization and the energy-dispersive X-Ray spectroscopy to describe the elemental chemical composition of the fibers. Chemical treatments using $\mathrm{NaOH}$ $2 \%$ and acetylation with acetic acid and acetic anhydride in the ratio $(1: 1,5)$ were important to observe the main changes such as the removal of impurities and the smaller amount of water absorbed in the acetylated fiber, which allows a better adhesion of the fibers with a polymer. After this, the fibers can be used to the production of polypropylene and polyethylene composites that are expected to apply in automotive parts such as bumpers, fuel tanks and internal coatings.

Keywords: Composites; Sisal fibers; Acetylation; Chemical treatment. 


\section{INTRODUÇÃO}

$\mathrm{Na}$ busca por materiais mais resistentes e com custo mais baixo, muitas pesquisas utilizam matérias-primas naturais que possam ser empregadas na fabricação de materiais denominados compósitos. Compósitos são materiais produzidos a partir da combinação de dois ou mais componentes de naturezas distintas, de modo que o resultado da combinação das propriedades de seus constituintes contribua para melhorar as características do produto final. Um compósito geralmente é formado por duas fases: matriz e fase dispersa. A primeira pode ser um material polimérico, metálico ou cerâmico e envolve a segunda, que podem ser materiais particulados ou fibras. A combinação desses elementos se faz bastante presente em utensílios domésticos, veículos, edifícios, visto que a tecnologia impulsiona 0 aprimoramento de materiais tradicionais, cujas aplicações para as quais são destinadas não são supridas sem essa associação. Em geral, melhoram as propriedades mecânicas como força, dureza, rigidez do produto e é dito que o reforça (MILTON, 2002).

Os plásticos sintéticos precisaram de mudanças devido ao forte impacto ambiental quanto ao processo de degradação. Vilaplana e colaboradores (2010), citado por Calegari e Oliveira (2016), afirmam que a utilização de materiais biodegradáveis auxilia na diminuição da emissão de poluentes, bem como se tornam alternativas viáveis em relação ao uso dos derivados de petróleo. Com isso, pesquisas envolvendo o uso de fibras naturais como material de reforço na produção de compósitos, tem despertado o interesse na indústria, uma vez que elas possuem baixa densidade, menor abrasividade e podem melhorar a resistência mecânica a um custo menor, quando comparadas ao emprego de fibras sintéticas como a fibra de vidro (CALEGARI e OLIVEIRA, 2016).

Estas fibras naturais podem ser de origem animal, vegetal ou mineral. Existem diversas aplicações para compósitos produzidos à base de fontes renováveis (Figura 1). Por exemplo, embalagens para armazenamento de ovos e frutas produzidas a partir de fibra de coco e amido de mandioca podem substituir as de papelão ou isopor; acessórios para ferramentas de jardinagem à base de gelatina e serragem em substituição ao alumínio e madeira ou ao polipropileno; vasos para mudas de plantas a partir da casca de arroz ou da fibra de coco verde em substituição aos vasos de plástico ou cerâmica, dentre outras.

A exemplo disso, temos os "materiais verdes", que são importantes quando se trata de inovação e sustentabilidade (MACHADO et al., 2014). Considerando o uso destes materiais, nos últimos anos, fibras vegetais estão sendo utilizadas para produção de compósitos e na extração de outras substâncias como a lignina e a celulose, com o objetivo que varia desde aplicações médicas a emprego em áreas como construção civil e mecânica de automóveis (MIRANDA et al., 2015).

Segundo Gonçalves et al. (2018), as fibras vegetais possuem aplicações em vários setores como construção civil, indústria naval e automobilística, na área da saúde com os sistemas de liberação controlada de medicamentos à base de fibras, etc. Apresentam diversas vantagens, entre elas, ecológicas e econômicas, pois seus resíduos são facilmente absorvidos pela natureza, além da geração de empregos na economia local. Sua produção requer pouca energia e também possibilita a fabricação de materiais mais leves e resistentes, além de liberarem pouco dióxido de carbono ao meio ambiente quando expostas a processos de incineração ou compostagem.

Por outro lado, por absorverem água facilmente, as mesmas podem ser atacadas por fungos e bactérias, 0 que pode afetar 0 desempenho mecânico do compósito e implica na necessidade de tratamentos químicos que possam melhorar sua hidrofobicidade, consequentemente melhorando a sua adesão quando empregadas na produção de compósitos de matriz polimérica. (CARVALHO e CAVALCANTI, 2006). Outra desvantagem no uso de fibras vegetais lignocelulósicas é a limitação da faixa de temperatura (em torno de $220^{\circ} \mathrm{C}$ ), que implica em perda de massa e na degradação do material, com a queima da própria fibra. (MARINELLI et al., 2008)

As fibras vegetais podem ser duras ou moles e esta classificação é dada de acordo com - local de obtenção e também pela quantidade de lignina presente nas paredes secundárias. As fibras duras são obtidas dos feixes vasculares das folhas e possuem textura rígida e geralmente possuem teor de lignina superior ao das fibras macias. A principal aplicação é na fabricação de cordas, tapetes e tecidos grosseiros (LEVETIN e 
MCMAHON, 2016). De acordo com o site Só Biologia, podemos citar como exemplos as fibras de bambu, cana-de-açúcar, milho, banana, capim, trigo, coco e sisal. Por outro lado, as fibras macias são obtidas das hastes e são mais flexíveis e elásticas, com destaque para o linho, rami, eucalipto, mamona e soja.

Considerando o uso de fibras vegetais como materiais de reforço na produção de compósitos poliméricos, podemos citar algumas cultivadas no país e que são utilizadas na elaboração de novos materiais: coco, juta, sisal, bagaço da cana-de-açúcar, bambu, rami, soja, açaí, curauá, abacaxi, linho, miriti, algodão, entre outras (MARINELLI et al., 2008). Isto reduz a quantidade de polímero empregada, uma vez que a maioria dos polímeros é oriunda de derivados do petróleo. Além de ser uma alternativa economicamente viável, diminuindo inclusive o êxodo rural, atende à maioria das exigências em suas propriedades mecânicas, térmicas, elétricas e, em muitos casos, ocasiona melhorias nestas propriedades (ROSÁRIO et al., 2011).

O sisal (Agave Sisalana) é uma planta oriunda do México e que tem vasta aplicação, principalmente no que se refere ao uso de suas fibras (Figura 2). Chegou ao Brasil no início do século XX através do estado da Bahia. É considerada a fibra dura mais comercializada no mundo, sendo o Brasil um dos maiores exportadores. Além disso, é responsável por manter a economia local de diversos lugares devido ao processo de beneficiamento, que se inicia desde o cultivo da planta e se estende até a comercialização da fibra (MARTIN et al., 2009).

De acordo com Medeiros e colaboradores (2016), os principais produtores de sisal no Brasil se localizam na região Nordeste divididos entre: Bahia, com 95,8\% da produção total; Paraíba com 3,5\%, Ceará com $0,4 \%$ e Rio Grande do Norte com 0,3\%. Em 2016, o valor mínimo que o Governo Federal estabelecia era de $R \$ 1,73 / \mathrm{kg}$. Atualmente, de acordo com os dados obtidos em consulta no site do Ministério da Fazenda, o valor mínimo da fibra bruta beneficiada passou a ser $\mathrm{R} \$ 2,04 / \mathrm{kg}$, mais barata quando comparadas a outras fibras como juta ( $\mathrm{R} \$ 2,54 / \mathrm{kg}$; Região Norte) e piaçava ( $R \$ 2,47 / \mathrm{kg}$; Bahia e Região Norte). Estes valores foram estabelecidos em portaria regulamentada pelo próprio ministério e vigoraram entre junho de 2017 e junho de 2018. Já o valor do polipropileno virgem ficou na média de $R \$ 7,92 / \mathrm{kg}$, o que justifica o interesse de muitas indústrias em reduzir os custos com o polímero sem perder as boas propriedades que ele fornece aos materiais (PIRAMIDAL, 2018).

Wambua et al. (2003) estudaram o comportamento mecânico de compósitos de matriz de polipropileno com algumas fibras naturais e o sisal se destacou como a fibra que apresentou o melhor desempenho em relação à absorção de impacto. Em 2010, um levantamento feito por estudantes da Universidade do Porto (Portugal) mostrou que na indústria automobilística utiliza-se bastante o polipropileno e o polietileno na fabricação de peças como para-choques, painéis, tanques de combustível, sistemas de ar condicionado, airbag, revestimento da cabine, reservatório de água para limpeza do para-brisas, etc. A vantagem da utilização destes materiais é que reduzem a massa utilizada, de modo que a cada $300 \mathrm{~kg}$ de materiais tradicionais usados, só se utiliza $100 \mathrm{~kg}$ de polímeros para a produção da mesma quantidade de peças, reduzindo os custos com a produção e melhorando o uso dos espaços, além da economia de combustível (HEMAIS, 2003). Os compósitos poliméricos produzidos a partir do uso de fibras vegetais estão sendo utilizados nestas mesmas aplicações, com o objetivo de reduzir ainda mais os custos com a produção sem provocar perdas nas propriedades do novo material, além de facilitar o seu processo de degradação em casos de descartes inadequados.

Desde o início da década de 2000, o surgimento de novos materiais com maiores resistências à umidade, corrosão, erosão levaram ao desenvolvimento de novos plásticos como em alguns cones de exaustão de aeronaves, portas dos trens de aterrissagem, na fabricação de paraquedas, entre outros. A substituição de componentes metálicos de aeronaves por compósitos poliméricos, além de reduzir a massa da aeronave, possibilitou a redução no custo com as peças bem como melhorou a resistência ao impacto, à umidade e ao calor (REZENDE e BOTELHO, 2000).

Considerando as boas propriedades mecânicas que a inserção das fibras provoca no produto desejado, o objetivo deste trabalho foi analisar a modificação superficial de fibras de sisal, para uso posterior na fabricação de compósitos de matriz polimérica como polietileno e polipropileno. A partir destes materiais, desejase investigar a tensão máxima suportada e sua resistência ao impacto, para que possam ser 
utilizados na fabricação de para-choques e tanques de combustível de automóveis, uma vez que as atenda às exigências dos fabricantes $e$ reduza os custos com a produção. O processo de caracterização utilizou técnicas de infravermelho (FTIR), UV-Vis por Reflectância Difusa, microscopia eletrônica de varredura (MEV) e mapeamento por espectroscopia de raios $X$ por dispersão de energia (EDS) para determinar a composição elementar.

\section{PARTE EXPERIMENTAL}

A fibra vegetal utilizada como matériaprima para o desenvolvimento deste trabalho foi a fibra de sisal da espécie Agave Sisalana, adquirida em estabelecimentos comerciais na forma de rolo de corda. O procedimento experimental foi realizado no Laboratório de Mecânica da Fratura e Fadiga (LAMEFF), vinculado ao Departamento de Engenharia Metalúrgica e de Materiais da Universidade Federal do Ceará (UFC). A corda foi desfiada, de modo a separar as fibras uma por uma. Em seguida, foram cortadas no tamanho de $20 \mathrm{~cm}$. A escolha do tamanho foi atribuída a adaptação de metodologia já utilizada em estudos anteriores por pesquisadores do LAMEFF (DE MELO, 2016). Após a separação e corte das fibras, estas foram divididas em dois grupos: uma parte foi submetida ao tratamento químico e a outra não foi tratada.

\subsection{Tratamento Químico das Fibras}

Além do baixo custo na obtenção de fibras vegetais, a possibilidade de modificação por meio de tratamentos químicos, torna cada vez mais comum a utilização como agente de carga e reforço em compósitos com matrizes poliméricas. Para melhorar a adesão das fibras com uma matriz, em especial, polimérica, é preciso submeter às fibras a alguns tipos de tratamento químico, com destaque para a mercerização e a acetilação. Estes tratamentos modificam a superfície da fibra e também alteram suas propriedades mecânicas como tensão, módulo de elasticidade e alongamento na ruptura (ALBINANTE et al., 2012).

\subsubsection{Processo de lavagem}

Em se tratando da composição química das fibras naturais, a maior parte é composta por celulose, hemicelulose e lignina, além de gorduras e ceras (ALBINANTE et al.,2012). Para remover o excesso dessas substâncias, as fibras precisam ser lavadas antes de qualquer tipo de tratamento químico. Desta forma, esta etapa consistiu na imersão das fibras em água destilada à $80^{\circ} \mathrm{C}$ durante uma hora. Após a lavagem, foram secadas em uma estufa à $60^{\circ} \mathrm{C}$. Esse processo de lavagem foi repetido intercalando entre os processos de mercerização e acetilação. A principal característica observada durante esse processo foi a mudança na coloração da água que era descartada, indicando a eliminação principalmente de lignina e hemicelulose.

\subsubsection{Mercerização}

Foram imersos $10 \mathrm{~g}$ de fibras de sisal em $250 \mathrm{~mL}$ de solução de $\mathrm{NaOH} 2 \%$, à temperatura de $60^{\circ} \mathrm{C}$ e sob agitação constante durante uma hora. Este processo visa remover substâncias que são solúveis em ambiente alcalino. Repetiuse o procedimento outras duas vezes e, entre as repetições, as fibras foram lavadas como descrito no item acima, até atingir a neutralidade com $\mathrm{pH}=7$ (JESUS et al., 2015).

\subsubsection{Acetilação}

De acordo com o artigo de $\mathrm{Li}$ e colaboradores (2007), a acetilação de fibras naturais é um tipo de tratamento químico que consiste na modificação da parede celular da fibra, de modo que a substituição dos grupos hidroxilas $(-\mathrm{OH})$ pelo grupo acetil $\left(\mathrm{CH}_{3} \mathrm{COO}-\right)$ seja capaz de tornar a fibra hidrofóbica, reduzindo a higroscopicidade e melhorando a adesão interfacial fibra-matriz. Contudo, para que este processo aconteça é preciso antes que as fibras sejam tratadas em meio alcalino por meio da mercerização. Para a realização do procedimento de acetilação das fibras, a metodologia foi adaptada de D'Almeida e colaboradores (2005). Após mercerizadas, as fibras foram imersas em uma solução de ácido acético e anidrido acético na proporção $(1: 1,5)$, com adição de 5 gotas de ácido sulfúrico $\left(\mathrm{H}_{2} \mathrm{SO}_{4}\right)$ para $250 \mathrm{~mL}$ de solução, à temperatura de $80^{\circ} \mathrm{C}$. Esta adaptação ocorreu porque em temperaturas mais elevadas a fibra sofreu mais degradação que o necessário. Após acetiladas, as fibras foram lavadas como descrito no processo de lavagem e secadas em estufa à $60^{\circ} \mathrm{C}$.

\subsection{Infravermelho por Transformada de Fourier (FTIR)}


Os espectros foram obtidos em um equipamento IRTracer-100 na faixa de 400 a $4000 \mathrm{~cm}^{-1}$ com uma resolução de $1 \mathrm{~cm}^{-1}$. As amostras foram colocadas na forma de filme pulverizado e prensadas em pastilha de $\mathrm{KBr}$. A técnica indica as vibrações moleculares existentes na amostra analisada e auxilia na identificação de grupos funcionais mostrando suas bandas de absorção na região do infravermelho no espectro eletromagnético. As fibras foram analisadas antes, durante e depois dos tratamentos químicos de modo a observar a presença ou ausência de grupos funcionais característicos (HOLLER et al., 2009).

\subsection{UV-Vis Por Reflectância Difusa}

Os espectros de UV-VIS foram obtidos em um equipamento espectrofotômetro UV-Vis, modelo Shimadzu UV-2600 com esfera integradora ISR-2600 Plus e foram traçados no comprimento de onda de 200 a $500 \mathrm{~nm}$, usando cubeta de quartzo com um percurso óptico de 1 $\mathrm{cm}$. O próprio software integrado ao equipamento forneceu os dados de reflectância e absorbância em função do comprimento de onda, conhecido como Kubelka Munk (SÁENZ-TREVIZO et al., 2016). Foram analisadas as fibras de sisal sem tratamento (natural), tratadas com $\mathrm{NaOH} 2 \%$ e acetiladas. A partir destes dados foi possível obter a energia de "band gap" bem como identificar algumas transições eletrônicas características de algum dos constituintes do material.

\subsection{Microscopia Eletrônica de Varredura (MEV) e Espectroscopia por Energia Dispersiva (EDS)}

Para analisar a morfologia da superfície das fibras, as micrografias obtidas por Microscopia Eletrônica de Varredura (MEV) foram realizadas na Central Analítica da UFC. O microscópio utilizado foi o Inspect S5-FEI para a avaliação da superfície antes e depois do tratamento químico. As amostras foram coladas junto ao stub com fita de carbono de dupla colagem e cobertas com Au usando uma metalizadora QT150 ES-Quorum, possibilitando a análise em MEV de alta tensão, pois havia necessidade de descarga dos elétrons que atingiram o material sem riscos de degradá-lo. Ajustando o MEV para 20,00 kV, foram analisadas a superfície das fibras para aumentos variando entre 100 e 3.000 vezes.
Para verificar os componentes da fibra de sisal, foi realizada uma análise por EDS. A técnica é válida para determinar elementos de número atômico maior que 11 e engloba um acessório de um microscópio eletrônico que consiste em determinar quais elementos químicos podem estar presentes em uma amostra. Baseia-se em um feixe de elétrons que incide sobre uma amostra, excitando os elétrons e liberando energia da ordem de comprimento dos raios $\mathrm{X}$, permitindo gerar o mapeamento da composição da amostra, uma vez que cada elemento possuir um valor característico de energia. (SOTO, 2015).

\subsection{Ensaio de intumescimento}

Com a finalidade de se verificar os efeitos dos tratamentos químicos sobre a capacidade de sorção de água pelas fibras, realizou-se um ensaio de intumescimento. Para isso, as fibras natural, mercerizadas e acetiladas inicialmente foram pesadas em uma balança semianalítica. Em seguida, foram imersas em água e em intervalos de tempo pré-determinados, as mesmas eram retiradas e após a remoção do excesso de água eram pesadas novamente. $O$ grau de intumescimento (G.I) foi calculado pela diferença entre a massa da fibra úmida $\left(M_{u ́ m}\right)$ e a massa da fibra seca $\left(M_{\text {seca }}\right)$ dividida pela massa da fibra seca $\left(\mathrm{M}_{\text {seca }}\right)$ de acordo com a Eq.1 (CRUZ et al., 2016).

$$
\text { G.I. }(\%)=\left[M_{u ́ m}-M_{\text {seca }} / M_{\text {seca }}\right] \times 100
$$

\section{RESULTADOS E DISCUSSÃO:}

O objetivo de caracterizar as fibras e submetê-las ao tratamento químico foi para que possam ser usadas na produção de compósitos. Compósitos são materiais constituídos por componentes de naturezas distintas com propriedades intermediárias resultantes de uma combinação destes materiais, de modo que ambos os componentes contribuam para melhorar as características do produto final. Em geral, há melhoria nas propriedades mecânicas como o aumento na força, dureza, rigidez do produto e é dito que o reforça. Geralmente são formados por duas fases: matriz e fase dispersa. A primeira pode ser um material polimérico, metálico ou cerâmico e envolve a segunda que podem ser materiais particulados ou fibras. A combinação desses elementos se faz bastante presente, visto que a tecnologia impulsiona 0 aprimoramento de materiais tradicionais cujas 
aplicações para as quais são destinadas não são supridas sem essa associação (NETO e PARDINI, 2006).

Segundo Mohan e Kanny (2012), o processo de mercerização é o tratamento químico mais utilizado com a finalidade de melhorar a adesão entre a fibra e a matriz. Favaro et al. citado por estes autores estudaram a modificação na superfície da fibra e observaram que a modificação é atribuída ao grupo hidroxila da celulose presente. Logo, este estudo foi importante para identificar os principais grupos funcionais presentes e/ou ausentes nas fibras de sisal natural, tratada com $\mathrm{NaOH} 2 \%$ e acetilada com ácido acético e anidrido acético na proporção $(1: 1,5)$ com adição de gotas de $\mathrm{H}_{2} \mathrm{SO}_{4}$ concentrado como catalisador.

\subsection{Espectroscopia de Infravermelho com Transformada de Fourier}

Os espectros de infravermelho forneceram algumas bandas de absorção características de estiramentos ou deformações e comprovaram a eficiência dos tratamentos químicos (Figura 3). Na fibra natural a banda de $1047 \mathrm{~cm}^{-1}$ foi atribuída as deformações nos acoplamentos $\mathrm{C}-\mathrm{H}$ e C-O. Os picos em $560 \mathrm{~cm}^{-1}$ e $897 \mathrm{~cm}^{-1}$ corresponderam a deformação $\mathrm{C}-\mathrm{OH}$ $\mathrm{e}$ as ligações $\beta$-glicosídicas existentes na hemicelulose (Lu et al. 2003 citado por Lopes et al., 2009).

As vibrações em $1246 \mathrm{~cm}^{-1}$ e $1318 \mathrm{~cm}^{-1}$ foram atribuídas ao estiramento $\mathrm{C}-\mathrm{O}$ e ao grupo acetil na lignina e hemicelulose. As bandas em $1371 \mathrm{~cm}^{-1}$ e $1427 \mathrm{~cm}^{-1}$ indicaram deformação C$H$ presente na celulose e hemicelulose e deformação $\mathrm{C}-\mathrm{H}$ lignina, respectivamente. Em $2920 \mathrm{~cm}^{-1}$ tivemos deformações axiais nas ligações C-H alifáticas e $2858 \mathrm{~cm}^{-1}$ grupos $-\mathrm{CH}_{2}$ associados à celulose e hemicelulose. Outro pico importante relacionado à estrutura da lignina foi em $1509 \mathrm{~cm}^{-1}$, correspondente a um estiramento $\mathrm{C}=\mathrm{C}$ do anel aromático. Na fibra natural, a banda em $1737 \mathrm{~cm}^{-1}$ foi referente ao estiramento $\mathrm{C}=\mathrm{O}$ na ligação éster na estrutura da hemicelulose. Houve uma diminuição na intensidade destas bandas, em especial do estiramento $\mathrm{OH}$ referente a hidroxila da água, diminuindo a capacidade de absorção de água, sendo mais evidente no processo de acetilação (SANJAY et al., 2018).

Podemos justificar a ausência das bandas de absorção $1246 \mathrm{~cm}^{-1}$ e $1737 \mathrm{~cm}^{-1}$ observadas no espectro de infravermelho da fibra mercerizada por conta da hidrólise alcalina que ocorre, na qual a lignina foi removida parcialmente, tornando a parede celular da fibra menos rígida (MIRANDA et al., 2015). Houve desaparecimento das bandas $1246 \mathrm{~cm}^{-1}$ referente a C-O lignina e $1738 \mathrm{~cm}^{-1} \mathrm{C}=\mathrm{O}$ hemicelulose (MOURA et al., 2016). Na fibra acetilada, as bandas $1236 \mathrm{~cm}^{-1}$ e $1756 \mathrm{~cm}^{-1}$ surgiram mais acentuadas e isto foi atribuído aos estiramentos dos grupos $\mathrm{C}-\mathrm{O}-\mathrm{C}$ e $\mathrm{C}=\mathrm{O}$. Isto indicou que o grupo acetil foi inserido nas fibras, modificando-as quimicamente.

\subsection{UV-Vis por Reflectância Difusa}

Em se tratando de cadeias de polímeros temos que muitos são conjugadas, isto é, alternam sequências de ligações simples e duplas. Assim, temos elétrons desemparelhados que constituem bandas de energia devido aos processos de oxidação ou redução que ocorrem nas cadeias poliméricas (PADILLA, 2011).

A lignina presente nas fibras possui banda de absorção máxima em $280 \mathrm{~nm}$ e a coloração da fibra é em função dessa absorção da luz pela lignina (PASTORE et al., 2008). A banda em 286 nm (Figura 4) equivale a transição eletrônica $\pi \rightarrow \pi^{*}$ correspondente ao anel aromático de unidades fenólicas não-conjugadas relacionadas à estrutura química da lignina (MING-FEl et al., 2012). A remoção da lignina é fundamental, uma vez que em sua cadeia polimérica há muitas conjugações e isto poderia diminuir o valor de "band gap", devido aos elétrons $\pi$ existentes. As transições eletrônicas do espectro vibracional estão relacionadas ao respectivo nível eletrônico, de modo que quanto maior conjugação, menor a energia de "band gap" e maior o momento de dipolo de transição (VISSOTO, 2015).

A introdução do sódio devido ao processo de mercerização faz com que o valor de "band gap" diminua, uma vez que em solução aquosa o $\mathrm{NaOH}$ se dissocia liberando os íons $\mathrm{Na}^{+}$e $\mathrm{OH}^{-}$. Com a acetilação, a fibra tem seu caráter covalente aumentado, o que justifica o elevado valor de "band gap", característica de um material isolante. A acetilação provocou a retirada dos grupos tornando maior a hidrofobicidade e alterando as interações eletrostáticas (remoção de impurezas com natureza condutora), elevando o caráter 
covalente.

Os valores de comprimento de onda obtidos na tabela foram calculados a partir de uma reta tangente colocada no ponto de menor absorção no espectro de reflectância (Figura 5). Esse valor foi substituído na equação $E_{\text {gap }}=$ $1240 / \lambda$ e então encontrou-se os valores para a energia das bandas (Tabela 1). Os resultados obtidos com os valores de "band gap" complementaram as demais análises mostrando que o tratamento nas fibras possibilitou a retirada de impurezas e de estruturas muito conjugadas, aumentando o caráter covalente e possibilitando a fibra uma melhor adesão superficial com uma matriz polimérica (MORO et al., 2012).

\subsection{Análise da superfície por Microscopia Eletrônica de Varredura}

A partir das micrografias eletrônicas obtidas na Central Analítica da UFC, foi possível observar as diferenças entre a superfície das fibras tratada e não tratadas (LOPES et al., 2009). A análise morfológica levou em consideração os parâmetros utilizados por Faria et al. (2017). Informações como tamanho dos poros e rugosidade, considerando o tipo de tratamento empregado na fibra. Observando as micrografias obtidas notou-se que a fibra natural apresentava células parenquimatosas e em algumas partes da superfície havia aspecto rugoso e impurezas incrustadas, o que pôde ser atribuído aos resíduos como óleos e ceras que foram removidos apenas com tratamento químico (Figura 6).

Contudo, a fibra mercerizada mostrou uma superfície com mais poros e rugosidade maior se comparada à fibra não tratada (Figura 7). Isto ocorreu devido a remoção de muitos componentes da fibra, com destaque para a remoção parcial da lignina. Durante o processo de lavagem que intercalava a etapa de mercerização, a coloração da água de descarte foi mais escura até o momento em que estabilizou e não mudou de cor.

No caso da fibra acetilada, o principal objetivo foi tornar a fibra mais hidrofóbica, uma vez que se introduziu o grupo acetil. Quanto à superfície foi mais lisa e uniforme, com menos poros e menor rugosidade, o que caracterizou uma fibra com maiores possibilidades de adesão a uma matriz polimérica, uma vez que sua polaridade foi reduzida (Figura 8).

\subsection{Análise do Mapa de Composição Química por EDS}

Através do mapa de elementar por EDS, foi percebido que a fibra natural apresentou $\mathrm{C}$ e O como seus principais constituintes, mas apareceram também $\mathrm{K}, \mathrm{Ca}, \mathrm{Mg}$ em pequenas quantidades, caracterizando impurezas (Figura 9). Estes elementos não fazem parte dos principais constituintes (lignina, celulose e hemicelulose) e estão associados aos nutrientes existentes no local de cultivo (BUITRAGO et al., 2015). Também foi observado, em quantidade pouco significante, $\mathrm{Si}, \mathrm{Al}, \mathrm{Fe}$, mas os valores permaneceram dentro do intervalo de ruído do equipamento. Com o tratamento alcalino à base de $\mathrm{NaOH}$, uma parcela dessas impurezas começou a desaparecer e surgiu no espectro um pico para o $\mathrm{Na}$, oriundo do $\mathrm{NaOH}$ (Figura 10). Com o processo de acetilação, as impurezas que apareciam na fibra natural, assim como sódio introduzido na mercerização foram removidos (Figura 11). O Au foi usado como cobertura e é associado ao processo de metalização da amostra. Mesmo com o tratamento, os percentuais de $\mathrm{C}$ e $\mathrm{O}$ pouco variaram entre as amostras.

\subsection{Resultados do Ensaio de Intumescimento}

Desta forma, foi possível analisar a absorção de água e verificar os efeitos dos tratamentos sobre a higroscopicidade das fibras, de modo a reforçar os resultados obtidos através das outras técnicas de caracterização. O ensaio durou 24 horas e foram observadas as massas com os tempos de imersão de $1 \mathrm{~h}, 2 \mathrm{~h}, 3 \mathrm{~h}, 4 \mathrm{~h}$, $10 \mathrm{~h}, 12 \mathrm{~h}$ e $24 \mathrm{~h}$. Observou-se que a partir da medida de 3 horas a massa de água absorvida se estabiliza e permanece constante até o final do ensaio (Tabela 2). Quanto menor o índice de absorção de água, maior a hidrofobicidade da fibra, o que implica que os grupos polares foram removidos, proporcionando melhorias na adesão com uma matriz polimérica para a produção de compósitos. Isto se comprovou, visto que a fibra acetilada apresentou a menor permeabilidade (55,5\% de absorção de água) se comparada a fibra mercerizada $(66,7 \%$ de absorção de água) e a fibra natural (77,8\% de absorção de água).

\section{CONCLUSÕES:}

Durante o processo de acetilação das 
fibras, a metodologia teve de ser readaptada com relação à temperatura e o tempo de exposição das fibras. Isto, porque nas primeiras fibras houve mais desfibrilação e os microfilamentos tornaram-se mais visíveis, de modo que a fibra sofreu mais degradação que o necessário. Com a técnica de microscopia eletrônica de varredura, foi possível caracterizar as modificações sofridas na superfície da fibra quando tratadas quimicamente. Esse processo foi feito buscando extrair informações que justificassem o uso da fibra de sisal como carga de reforço em compósitos com matriz polimérica de polipropileno virgem para possíveis aplicações na fabricação de peças automotivas.

\section{AGRADECIMENTOS}

Os autores gostariam de agradecer à Central Analítica UFC/CT-INFRA/MCTISISNANO/Pró-Equipamentos CAPES pelo suporte técnico nas análises de microscopia eletrônica e EDS; ao Departamento de Química Orgânica e Inorgânica da UFC pelas análises de infravermelho e UV-Vis, e a CAPES, pelo auxílio financeiro com a concessão de bolsa de estudos ao autor correspondente.

\section{REFERÊNCIAS:}

1. Milton, G. W.; The Theory of Composites, Cambridge University Press: Cambridge, 2002.

2. Calegari, E. P.; de Oliveira, B. F.; Sustentabilidade em Debate, 2016, 7, 140.

3. Materiais plásticos sustentáveis. Matéria Brasil, Disponível em:

<http://www.materiabrasil.com/materials>. Acesso em 13 jun. 2018.

4. Machado, Bruna A. S.; Reis, J. H. O.; da Silva, J. B.; Cruz, L. S.; Nunes, I. L.; Pereira, F. V.; Druzian, J. I.; Quim. Nova, 2014, 37,1275.

5. Miranda, C. S.; Fiuza, R. P.; Carvalho, R. F.; José, N. M.; Quim. Nova, 2015, 38, 161.

6. Gonçalves, F. A. C.; Amaral, E. L. S.; Lopes Júnior, J. L.; Lopes, B. L. S.;
Ribeiro Júnior, L. S.; Brabo, D. R.; Amarante, C. B.; Revista Espacios, 2018, 39, 12.

7. Carvalho, L. H. C.; Cavalcanti, W. S.; Polímeros: Ciência e Tecnologia, 2006, 16, 33.

8. Marinelli, A. L.; Monteiro, M. R.; Ambrósio, J. D.; Branciforti, M. C.; Kobayashi, M.; Nobre, A. D.; Polímeros: Ciência e Tecnologia, 2008, 18, 92.

9. Levetin, E.; McMahon, K.; Plants \& Society, $7^{\text {th }}$ ed., McGraw-Hill Education: New York, 2016.

10. Só Biologia. Disponível em: $<$ https://sobiologia.com.br/conteúdos/Rein os4/angiospermas2.php>. Acesso em 13 jun. 2018.

11. Rosário, F.; Pachekoski, W. M.; Silveira, A. P. J.; dos Santos, S. F.; Júnior, H. S.; Casarin, S. A.; Polímeros: Ciência e Tecnologia, 2011, 2, 90.

12. Nossa Ciência. Disponível em: <http://nossaciencia.com.br/noticias/pesq uisadores-da-paraiba-testam-extrato-desisal-contra-o-aedes-aegypti/>, Acesso em 14 jun. 2018.

13. Martin, A. R.; Martins, M. A.; Mattoso, L. H. C.; Silva, O. R. R. F.; Polímeros: Ciência e Tecnologia, 2009, 19, 40.

14. Medeiros, D. L.; Tavares, A. O. C.; Rozados, I. L. G.; dos Santos, E. S.; Viana, J. D., Rev. Virtual Quim., 2016, 8, 1166.

15. Tabela de Preços Mínimos Vigentes. Brasil, Ministério da Fazenda. Disponível em: <www.fazenda.gov.br/centrais-deconteudos/publicacoes/conjunturaeconomica/agricola/2018/tabela-deprecos-minimos-vigentes $>$. Acesso em 14 jun. 2018.

16. Piramidal, Preço do PP. Disponível em: <http://lojapiramidal.com.br/fabricante/4braskem.aspx>, Acesso em 14 jun. 2018. 
17. Wambua, P.; Ivens, J.; Verpoest, I.; Composites Science and Technology, 2003, 63, 1259.

18. Materiais usados na concepção de um automóvel. Faculdade de Engenharia, Universidade do Porto. Disponível em: $<$ https://web.fe.up.pt/ projfeup/cd_2010_1 1/files/MMM508_relatorio.pdf>. Acesso em 16 jun. 2018.

19. Hemais, C. A.; Polímeros: Ciência e Tecnologia, 2003, 13, 107.

20. Rezende, M. C.; Botelho, E. C.; Polímeros: Ciência e Tecnologia, 2000, $10, \mathrm{E} 4$.

21. de Melo, S. L. S.; Dissertação de Mestrado, Universidade Federal do Ceará, Brasil, 2016.

22. Albinante, S. R.; Pacheco, E. B. A. V.; Visconte, L. L. Y.; Quim. Nova, 2013, 36, 114.

23. Jesus, M. S.; Sousa, T.B.; Mori, F. A.; Guimarães, B. M. R.; O Papel, 2015, 76, 61.

24. Li, X.; Tabil, L. G.; Panigrahi, S.; J Polym Environ, 2007, 15, 25.

25. d'Almeida, A. L. F. S.; Calado, V.; Barreto, D. W.; d'Almeida, J. R. M.; Polímeros: Ciência e Tecnologia, 2005, 15, 59.

26. Holler, F. J.; Skoog, D. A.; Crouch, S. R.; Princípios de Análise Instrumental, $6^{a}$ ed., Bookman: Porto Alegre, 2009.

27. Sáenz-Trevizo, A.; Amézaga-Madrid, P.; Pizá-Ruiz, P.; Antúnez-Flores, W. Yoshida-Miki, M.; Materials Research, 2016, 19, 33.

28. Soto, I. I.; Tese de Doutorado, Universidade de São Paulo, Brasil, 2015.

29. da Cruz, J. B.; de Sá Catão, C. D.; Barbosa, R. C.; Fook, M. V. L.; Revista Matéria, 2016, 21, 129.

30. Neto, F. L.; Pardini, L. C.; Compósitos Estruturais - Ciência e Tecnologia, $1^{\underline{a}}$ ed. Edgard Blücher: São Paulo, 2006.
31. Mohan, T. P.; Kanny, K.; Composites: Part A, 2012, 43, 1989.

32. Lopes, F. F. M.; de Araújo, G. T.; do Nascimento, J. W. B.; Gadelha, T. S.; da Silva, V. R.; Revista Brasileira de Engenharia Agrícola e Ambiental, 2010, 14, 783.

33. Sanjay, M. R.; Madhu, P.; Jawaid, M.; Senthamaraikannan, Senthil, S.; Journal of Cleaner Production, 2018, 172, 566.

34. Moura, P. E. V.; Batista, M. V. S.; Mac Leod, T. C. O.; Anais do $22^{\circ} \mathrm{CBECimat} \mathrm{-}$ Congresso Brasileiro de Engenharia e Ciência dos Materiais, Natal, Brasil, 2016.

35. Padilla, R. M. A.; Tese de Doutorado, Pontifícia Universidade Católica do Rio de Janeiro - PUC-RIO, Brasil, 2011.

36. Pastore, T. C. M.; de Oliveira, C. C. K.; Rubim, J. C.; Santos, K. de O.; Quim. Nova, 2008, 31, 2071.

37. Li, M.F.; Sun, S.N.; Xu, F.; Sun, R.C.; Chemical Engineering Journal, 2012, 179, 80.

38. Vissoto, J. F. T.; Dissertação de Mestrado, Universidade Federal do Paraná, Brasil, 2015.

39. Moro, C. C.; Lansarin, M. A.; Bagnara, M.; Quim. Nova, 2012, 35, 1560.

40. de Faria, P. C.; Martin, A. A.; Alves, N. P.; Revista Matéria, 2017, 22.

41. Buitrago, B.; Jaramillo, F.; Gómez, M.; Journal of Natural Fibers, 2015, 12, 357. 

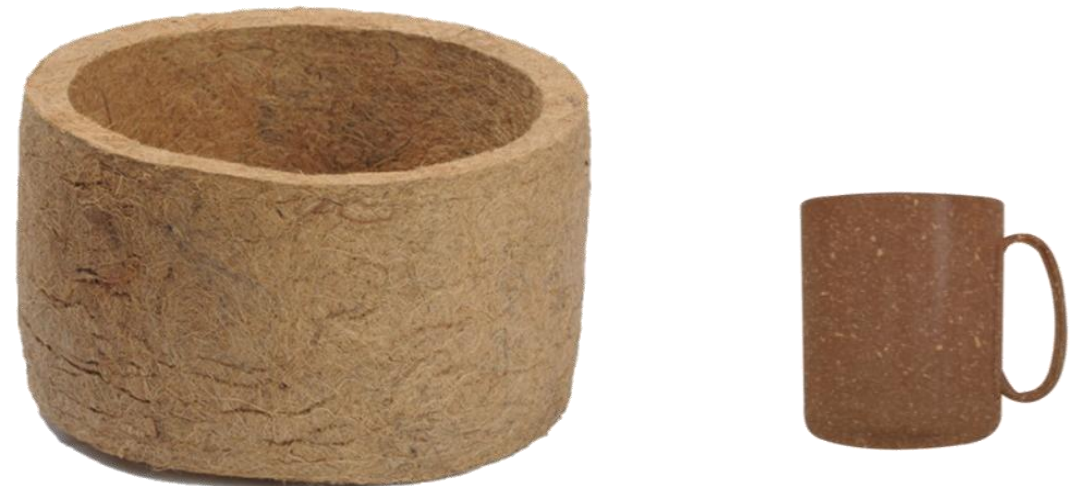

Fonte: Matéria Brasil.

Figura 1. Exemplos de materiais compósitos a partir de fibras vegetais: vaso de planta (à esquerda) e caneca em plástico polipropileno (à direita) à base de fibra de coco.

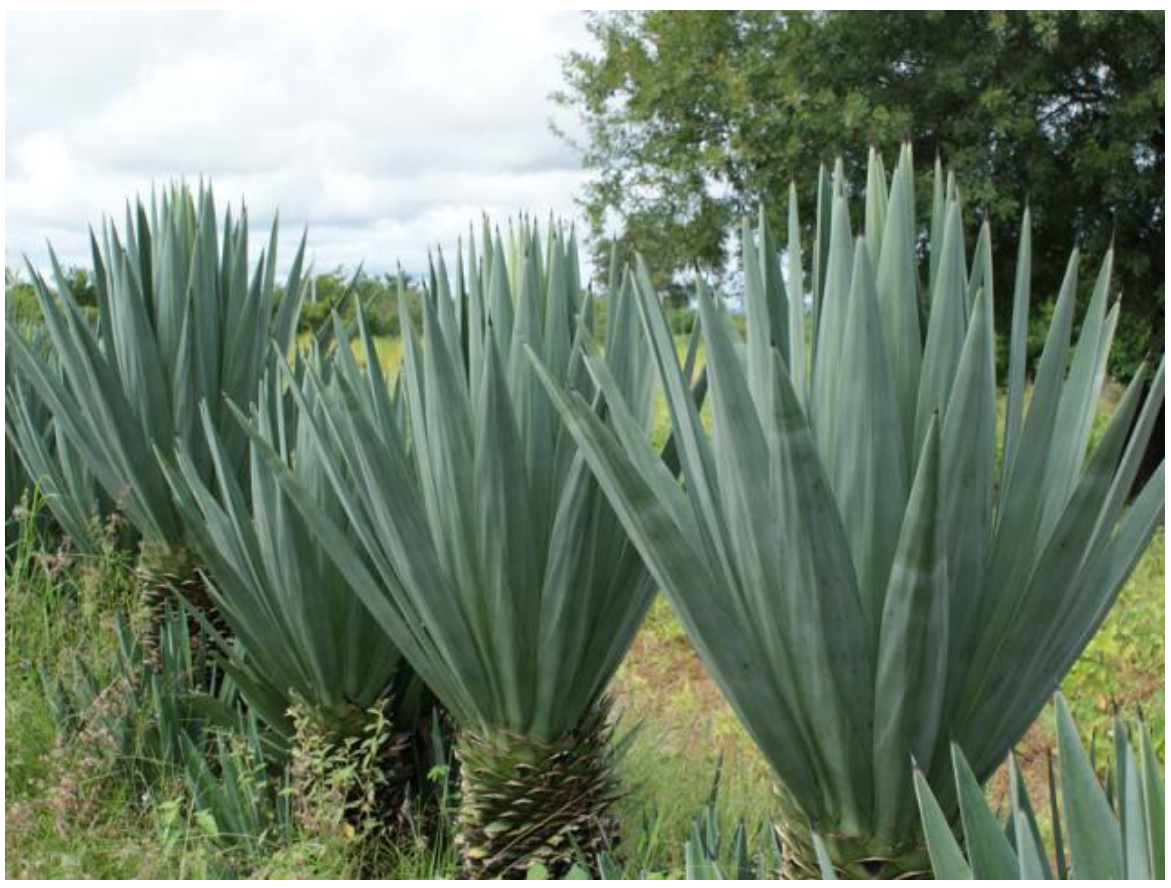

Fonte: Nossa Ciência.

Figura 2. Espécie de sisal (Agave Sisalana) da qual se extraem as fibras. 


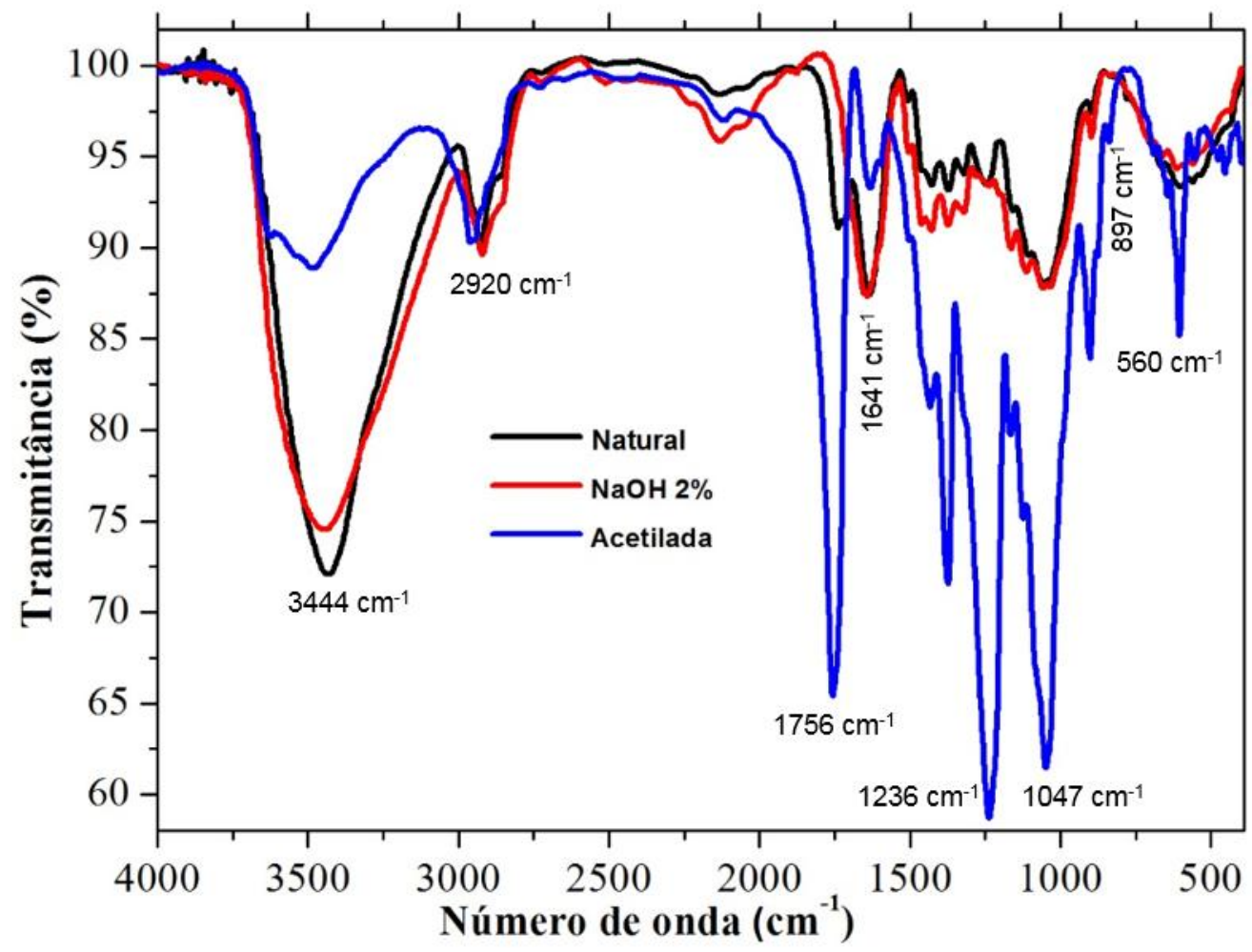

Figura 3. Espectro de infravermelho com as bandas para as fibras de sisal natural, tratada com $\mathrm{NaOH} 2 \%$ acetilada.

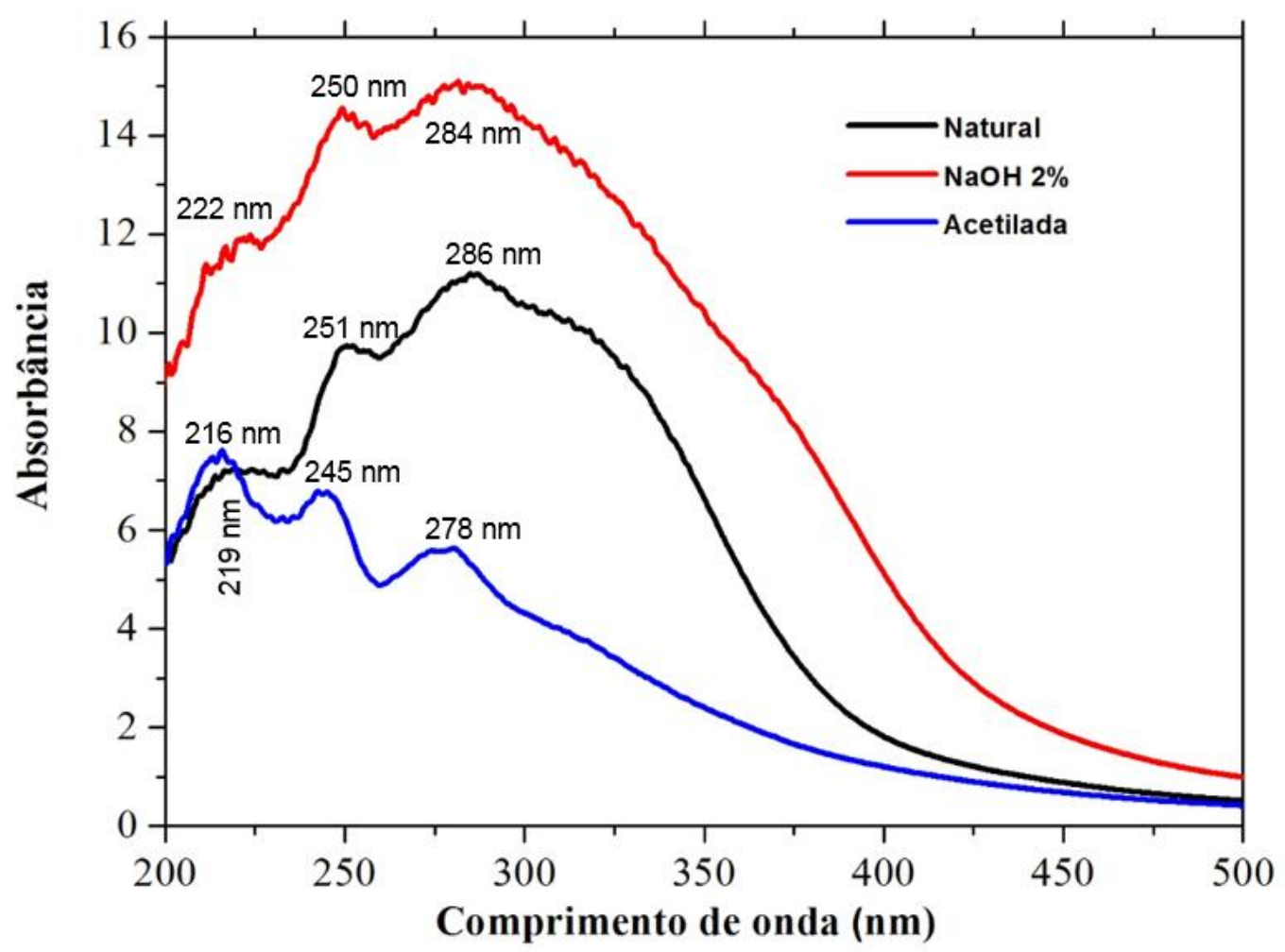

Figura 4. Espectro de UV-Vis obtido por Reflectância Difusa usando o método de Kubelka-Munk. 


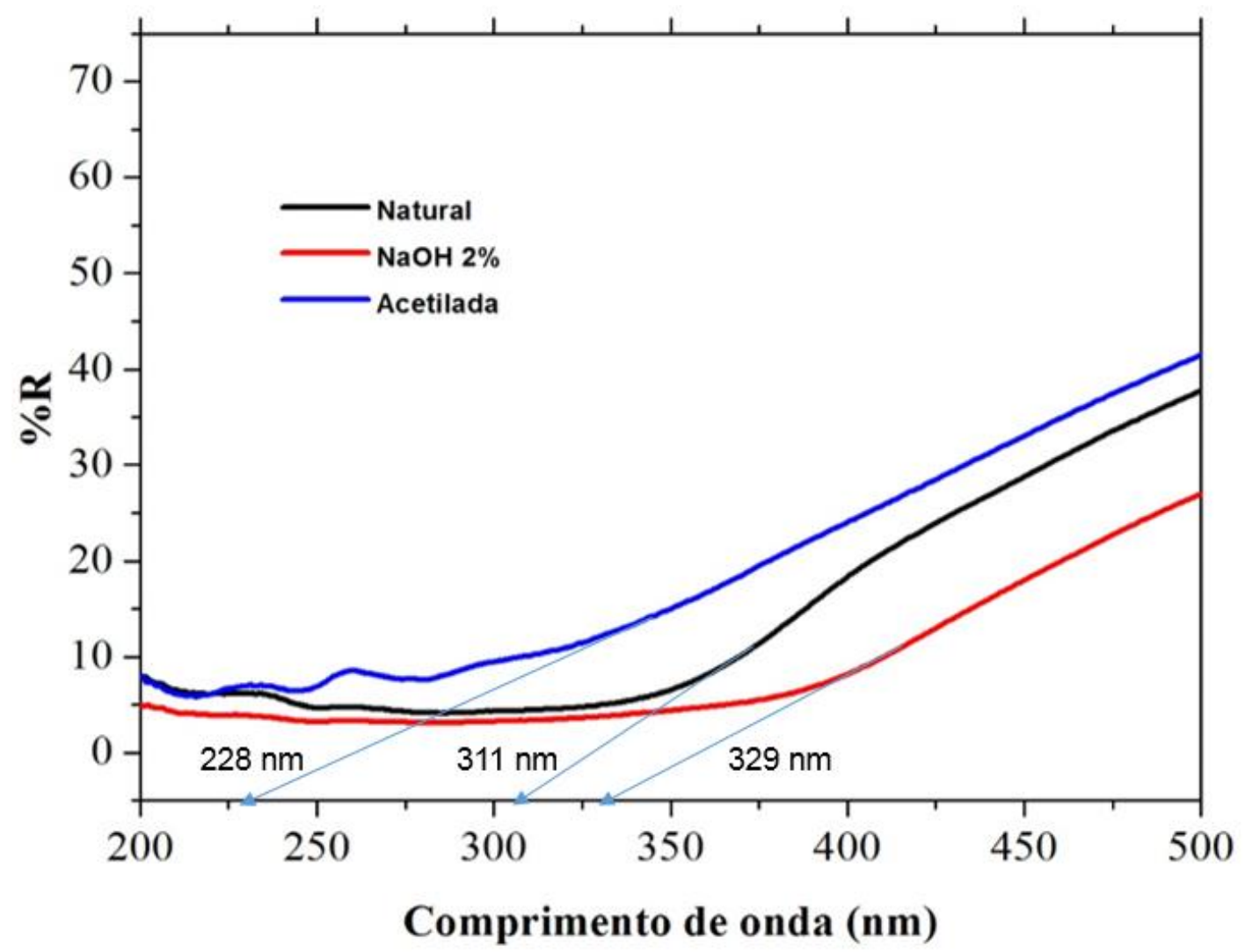

Figura 5. Espectro de UV-Vis obtido por Reflectância Difusa, com os valores mínimos de absorção obtidos traçando uma reta tangente para o cálculo da energia de "band gap".

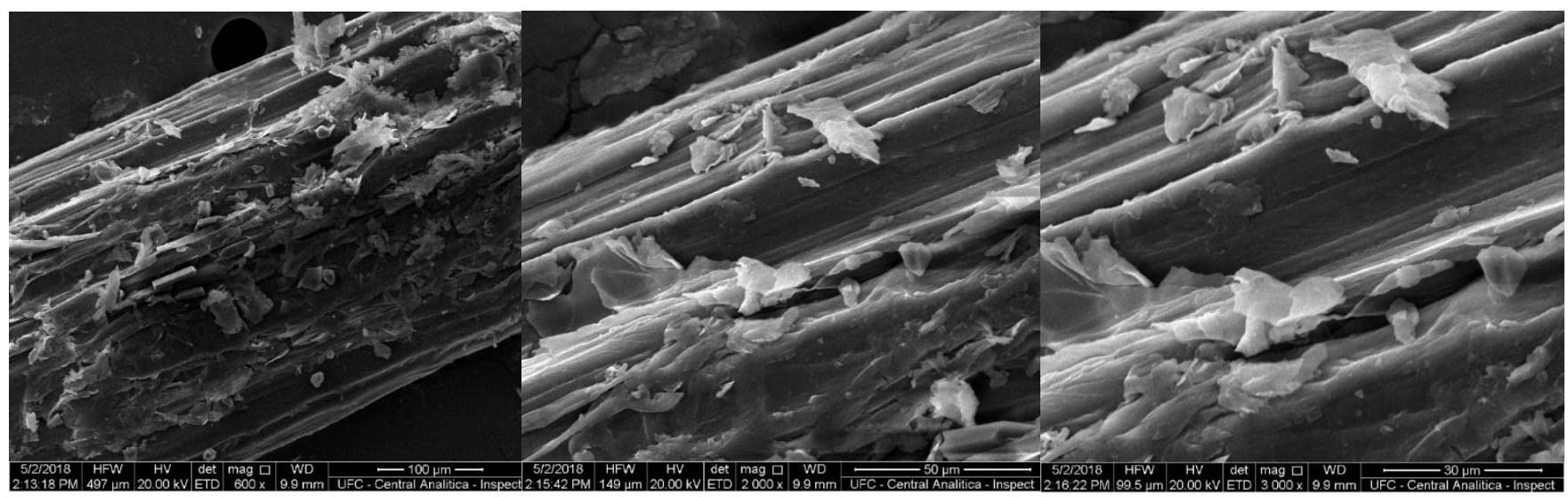

Figura 6. Micrografias obtidas em microscópio eletrônico de varredura para a fibra de sisal natural em aumentos de 600, 2000 e 3000 vezes. 


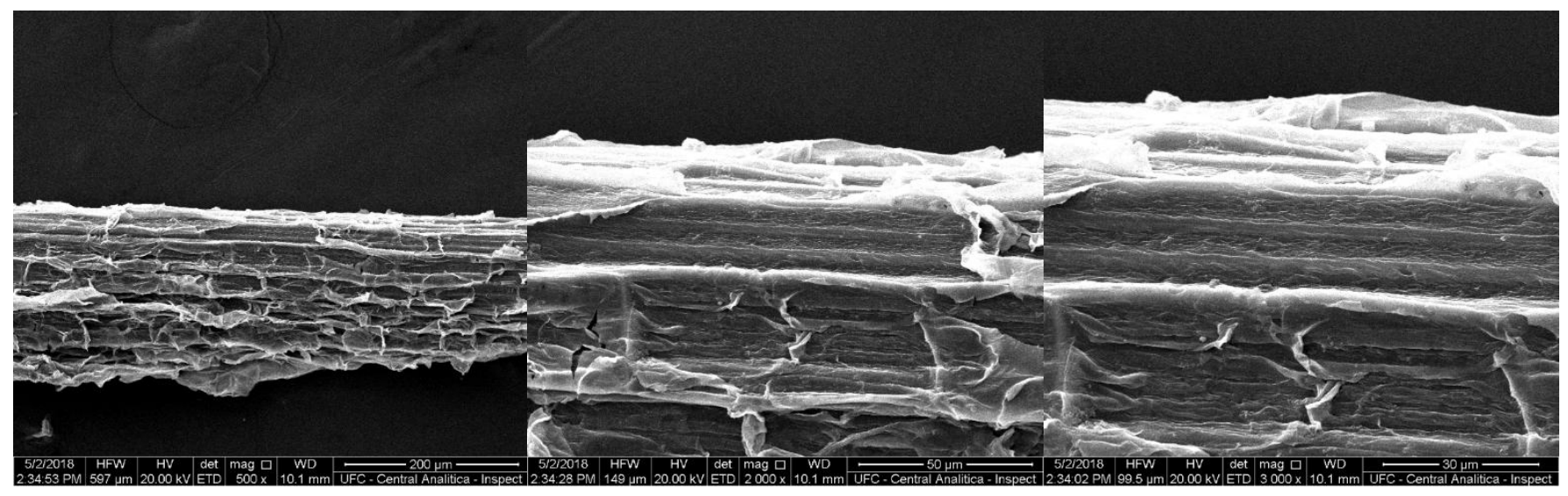

Figura 7. Micrografias obtidas em microscópio eletrônico de varredura para a fibra de sisal tratada com $\mathrm{NaOH} 2 \%$ em aumentos de 500, 2000 e 3000 vezes.

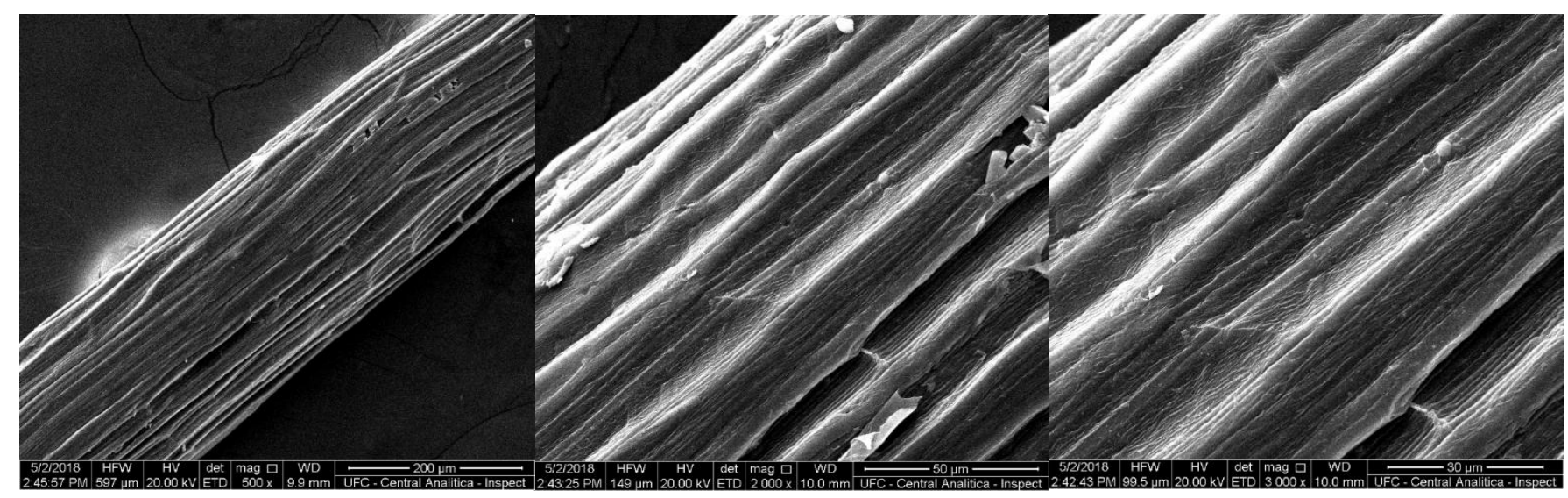

Figura 8. Micrografias obtidas em microscópio eletrônico de varredura para a fibra de sisal tratada com ácido acético e anidrido acético na proporção $(1: 1,5)$ em aumentos de 500,2000 e 3000 vezes. 


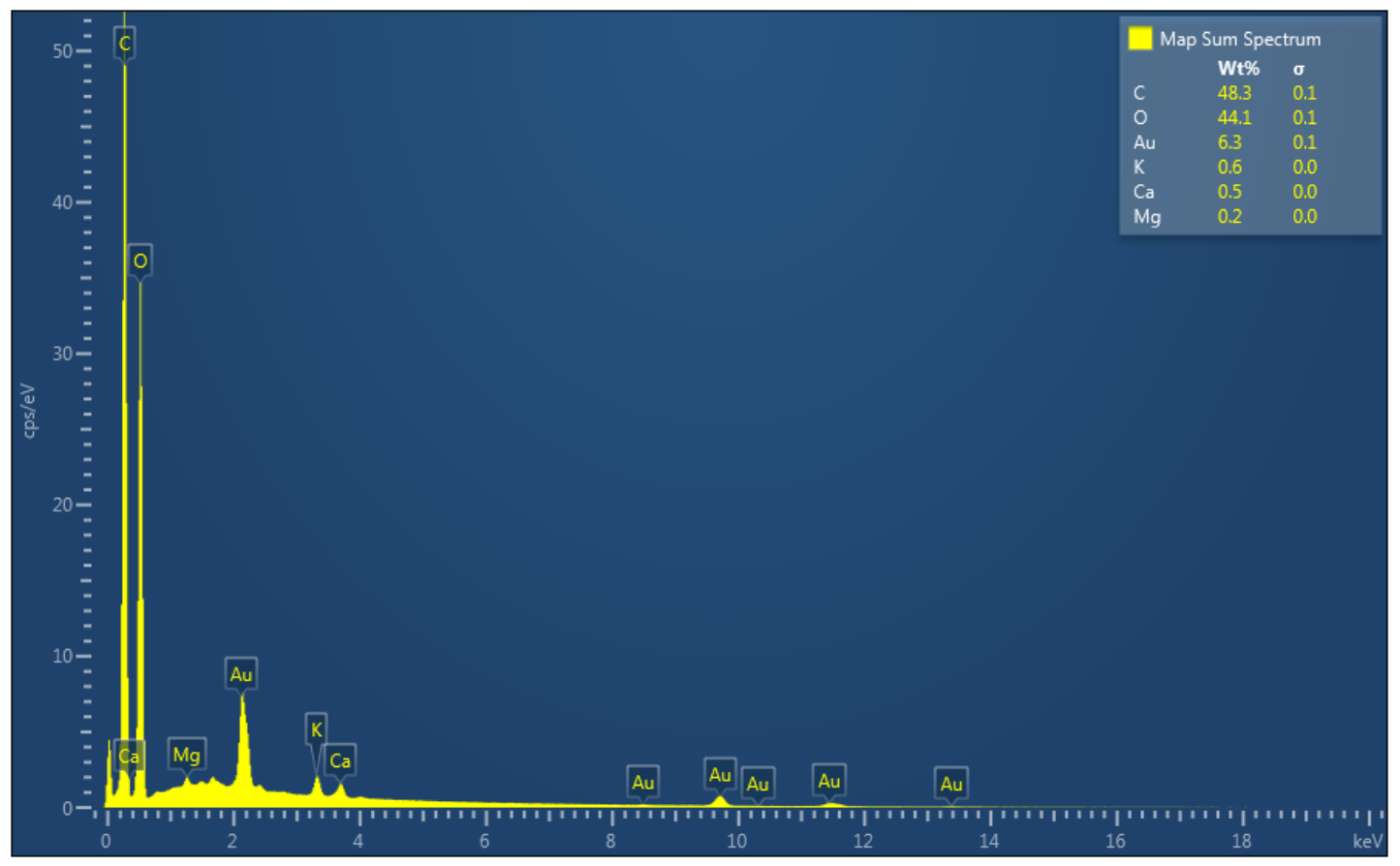

Figura 9. Mapeamento de EDS mostrando a composição química da fibra de sisal natural.

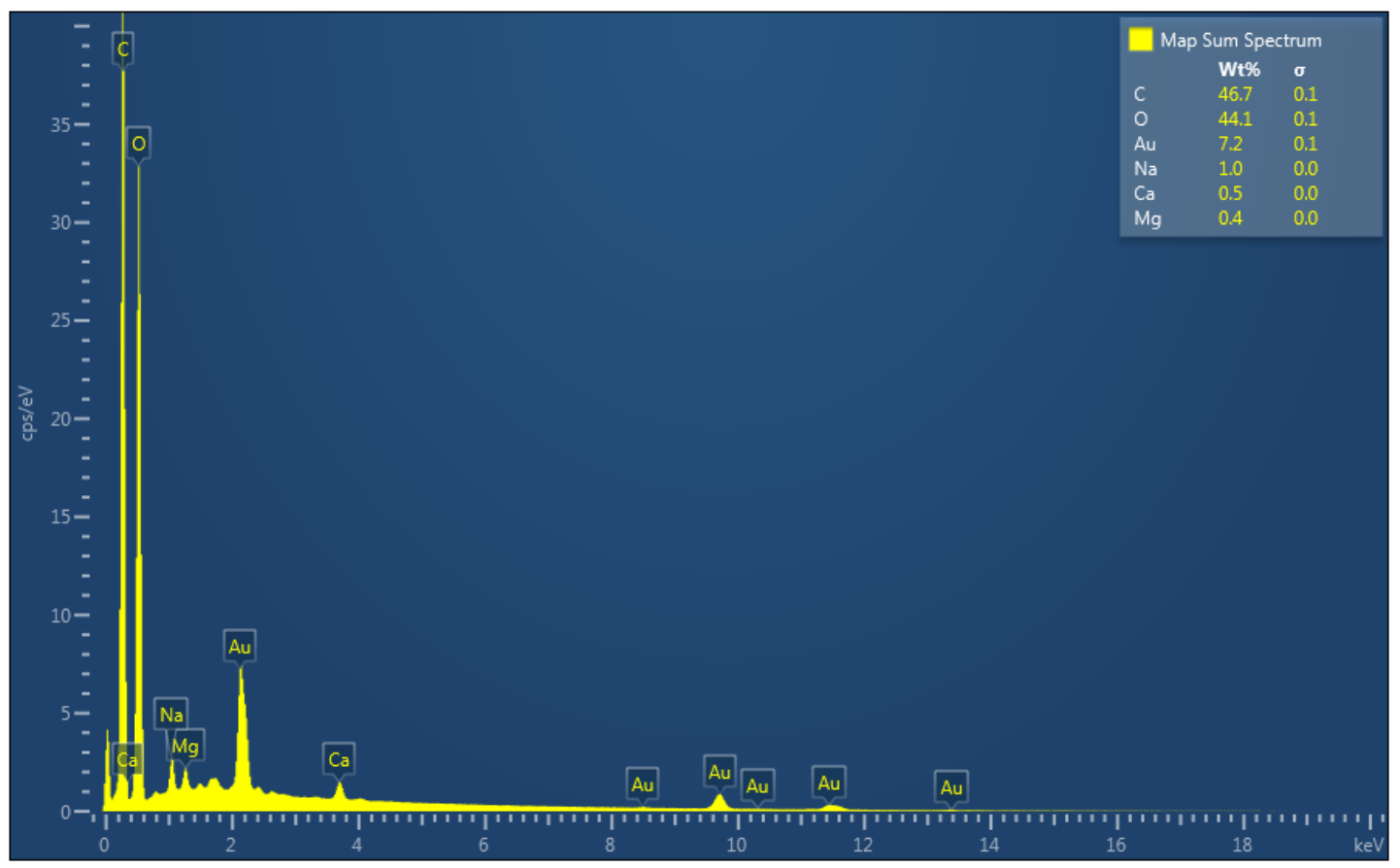

Figura 10. Mapeamento de EDS mostrando a composição química da fibra de sisal quando submetida ao tratamento com $\mathrm{NaOH} 2 \%$. Note que o elemento sódio ( $\mathrm{Na}$ ) surge no espectro.

PERIÓDICO TCHÊ QUÍMICA • www.periodico.tchequimica.com • Vol. 16 N. 31

- ISSN 1806-0374 (impresso) • ISSN 1806-9827 (CD-ROM) • ISSN 2179-0302 (meio eletrônico) 


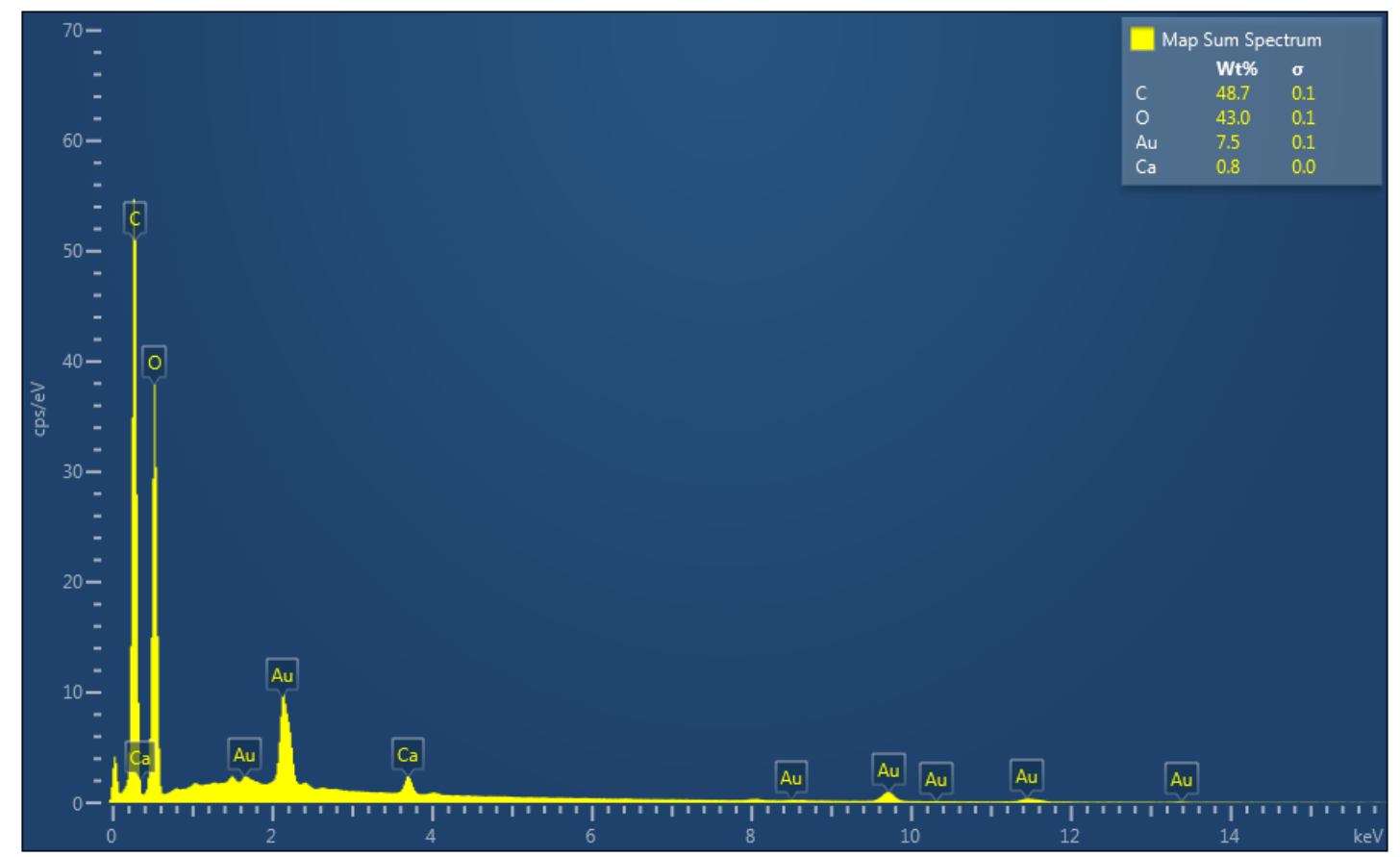

Figura 11. Mapeamento de EDS mostrando a composição química da fibra de sisal após o tratamento de acetilação. As impurezas que apareciam no espectro da fibra natural agora desapareceram.

Tabela 1. Valores de energia de "band gap" em função do comprimento de onda e do tipo de fibra.

\begin{tabular}{c|c|c}
\hline Tipo de Fibra & $\begin{array}{c}\text { Comprimento de } \\
\text { onda } \boldsymbol{\lambda}(\mathbf{n m})\end{array}$ & $\begin{array}{c}\text { "Band Gap" } \mathbf{E}_{\text {gap }} \\
\mathbf{( e V )}\end{array}$ \\
\hline Sisal natural & 311 & 3,98 \\
Sisal mercerizado & $329 \mathrm{e} 335$ & $3,77 \mathrm{e} 3,70$ \\
Sisal Acetilado & 228 & 5,44 \\
\hline
\end{tabular}

Fonte: Elaborado pelos autores, 2018.

Tabela 2. Resultados do ensaio de intumescimento das fibras, com imersão em água para verificar o grau de absorção de água.

\begin{tabular}{|c|c|c|c|c|c|c|c|c|c|}
\hline Fibra & $\begin{array}{c}\text { Massa } \\
\text { (g) } \\
\text { seca }\end{array}$ & $\begin{array}{c}\text { Massa } \\
\text { (g) } \\
\text { após } \\
1 \mathrm{~h} \\
\end{array}$ & $\begin{array}{c}\text { Massa } \\
\text { (g) } \\
\text { após } \\
2 \mathrm{~h}\end{array}$ & $\begin{array}{c}\text { Massa } \\
\text { (g) } \\
\text { após } \\
3 \mathrm{~h}\end{array}$ & $\begin{array}{c}\text { Massa } \\
\text { (g) } \\
\text { após } \\
24 \mathrm{~h}\end{array}$ & $\begin{array}{l}\text { G.I. } \\
\text { (\%) } \\
1 \mathrm{~h}\end{array}$ & $\begin{array}{l}\text { G.I. } \\
\text { (\%) } \\
2 \text { h }\end{array}$ & $\begin{array}{l}\text { G.I. } \\
\text { (\%) } \\
3 \text { h }\end{array}$ & $\begin{array}{l}\text { G.I. } \\
(\%) \\
4 \text { h }\end{array}$ \\
\hline & & $17,0 \mathrm{~g}$ & $16,0 \mathrm{~g}$ & $16,0 \mathrm{~g}$ & $16,0 \mathrm{~g}$ & 88,9 & 8 & 77,8 & 77,8 \\
\hline Mercerizada & & 1 & 15 & 15 & 15 & 77,8 & 66,7 & 66,7 & 66,7 \\
\hline Acetilada & $9,0 \mathrm{~g}$ & $14,0 \mathrm{~g}$ & $14,0 \mathrm{~g}$ & $14,0 \mathrm{~g}$ & $14,0 \mathrm{~g}$ & 55,5 & 55,5 & 55,5 & 55,5 \\
\hline
\end{tabular}

Fonte: Elaborado pelos autores, 2018.

PERIÓDICO TCHÊ QUÍMICA • www.periodico.tchequimica.com • Vol. 16 N. 31.

- ISSN 1806-0374 (impresso) • ISSN 1806-9827 (CD-ROM) • ISSN 2179-0302 (meio eletrônico)

(C) 2019. Porto Alegre, RS. Brasil 